now that several points might be bettered: again Service setting $(60.96 \%)$, booking service $(26.03 \%)$, waiting time $(15 \cdot 07 \%)$, even some technical-professional aspects $(22 \cdot 61 \%)$.
Conclusions: The SQ gives us useful ideas on how and where ameliorate, improve and remodel our standards, thus hopefully increasing the already high patients' compliance to the therapeutic process.

\title{
ACTIVE - Animation for Children to Teach and Influence Values and Views on healthy Eating and physical activity
}

\author{
M Vignolo ${ }^{1}$, A Parodi ${ }^{1}, C$ Torrisi ${ }^{1}$, V Fogliano ${ }^{2}, C_{\text {Giannetti }}{ }^{3}$, L Petito ${ }^{4}$, G Camozzini $^{4}$, \\ $\mathrm{S}$ Hughes $^{4}$, T Mbali ${ }^{4}, \mathrm{P}$ Tomasich ${ }^{5}$, S Borrelli ${ }^{5}, \mathrm{H}_{\text {Griffith }}{ }^{6}$ and L Gennaro ${ }^{3}$ \\ ${ }^{1}$ Centre for Prevention and Treatment of Childhood Obesity, University of Genoa, G. Gaslini Institute, Italy: \\ ${ }^{2}$ Department of Food Science, University of Napoli 'Federico II', Italy: ${ }^{3}$ INRAN (National Institute for Food and \\ Nutrition Research), Communications Office, Rome, Italy: ${ }^{4}$ Business Solutions Europa Limited, Ilford, UK: \\ ${ }^{5}$ Explora - The Children Museum of Rome, Italy: ${ }^{6}$ Griffilms LTD, Caernarvon, UK
}

Background: Children are not only becoming consumers as adults, but they also have a strong influence on their parents' shopping habits. They have also dramatically increased their TV exposure. Children (and their families) usually know the right things to do and eat, but do not always behave accordingly. Therefore an effective strategy to reach children should not give them only the knowledge of food, but also build a strong emotional participation in which our target can identify with and thus modify their behaviour. Health, intended as food and lifestyle, is not considered cool for children, and hence does not capture their interest; moreover, direct communication on health issues (made by adults and authorities who are not cool) is ineffective.

Aim: Nowadays there is no recent scientific literature about the television tool used to teach children healthy nutrition and lifestyle. On the other hand a wide number of researches stress the role of television (high levels of exposure to advertising of unhealthy foods, increase of sedentariness) as associated with overweight risk among children. Starting from this assumption, ACTIVE project has produced an animation that conveys messages in a new way that entertains and in a format that children enjoy watching and are captivated by. ACTIVE proposes an edutainment approach (informal education) to engage children aged $5-8$ years.

Method: ACTIVE has produced three episodes of a TV animation that tell positive and fun stories about breakfast, snacking and physical activity. Episodes are complemented by teaching packs to integrate the animation in schools (formal education). The partnership included animators, food and nutrition experts, TV and communication specialists and a pedagogic committee of five children museums and six schools from six European Union (EU) countries. An initial phase of content development involving the animation team and experts on food and nutrition has been conducted before the cartoon production: after an accurate analysis this partnership has defined an easily applicable universal European message.

A focus group of 600 children from six EU schools was created to evaluate the contents and the impact of the cartoon animation and the teaching pack with the help of three questionnaires: the first aimed to test the child's knowledge on food and nutrition provided information and creative inputs for scriptwriters. The second questionnaire aimed to evaluate the content of the first storyboard as well as the visual impact of the characters. This allowed the animators to adopt changes in due course. The third questionnaire allowed the children and their parents to give their view on the cartoon animation and was also used to test the teaching pack.

Results: Methodology and contents have been well received by heads of TV children programming. As from autumn 2010 episodes will be broadcast on TV in twenty countries and Teaching Pack will be available in sixteen languages.

Conclusions: There is a need to produce positive content to guide the learning path of younger generations. ACTIVE pilots a unique approach calling for stronger cooperation among the health community, creative industries and kids modernizing positive messaging about healthy lifestyles and physical activity. For more information visit www.animate-eu.com/active. Research relating to this abstract was funded by the Executive Agency for Health and Consumers in the framework of the EU Health Programme, Grant Agreement 20081225. 